\title{
Optimization of electronic sensors for detecting pollution due to organic gases using PARAFAC
}

\author{
Shri Om Mishra, S. Hasan Saeed \\ Department of Electronics and Communication Engineering, Integral University, India
}

\begin{tabular}{l}
\hline \hline Article Info \\
\hline Article history: \\
Received Nov 2, 2018 \\
Revised Feb 28, 2019 \\
Accepted Mar 22, 2019 \\
\hline
\end{tabular}

\section{Keywords:}

Electronic aroma detector

E-nose device

Multi sensor array

Odor concentration

Sensors

\begin{abstract}
The principle point of this examination work is to recognize the butane, Acetone, Propane, ethane, LPG and other natural gases from the strong waste and do condition checking. Here the arrangement of sensors used to identify the poison gases from strong waste. Here our point is to build up a sensor cluster framework which will identify most extreme contamination gases and which is very responsive, minimal effort and low power devouring. We have assumed three sensors in position of six sensors and given the outcomes as fluctuation, score plot and stacking plot. Here we utilize the parallel factor analysis (PARAFAC) for identification of gases and contrast it and the key part investigation Principal component analysis (PCA). We confiscated three sensors in position of six sensors and given the outcomes as variance, score plot and loading plot. Electronic noses have given a plenty of advantages in different logical research fields. Here our point is to build up a sensor exhibit framework which will distinguish most extreme contamination gases and which is profoundly responsive, exact and minimal effort and low power expending. Here we utilize the parallel factor investigation method (PARAFAC) for discovery of gases and contrast it and the primary segment examination (PCA).
\end{abstract}

Copyright () 2019 Institute of Advanced Engineering and Science. All rights reserved.

Corresponding Author:

Shri Om Mishra,

Department of Electronics and Communication Engineering,

Integral University,

Kursi Road, Dasauli, Lucknow, Uttar Pradesh, India.

Pin-226026

Email: shriom88m@gmail.com

\section{INTRODUCTION}

The goal of this work is upgrades in the segregation of complex smell tests with inconspicuous contrasts in scent design. The fundamental target is utilization of hydrocarbon compound database recognition utilizing diverse mix of nose sensors exhibit utilizing PARAFAC (parallel factor examination) technique. In this work we check the order precision of three hydrocarbons ethanol, propane gases at two measurement bunch space by PARAFAC. Take distinctive kinds of sensor exhibit blend to produce PARAFAC reaction more than two key parts. Gauge group covering of all the three(Acetone, Ethanol, propane) match of gases and the change of bunches, utilizing these outcomes we will at last discover best sensor exhibit mix set having least number of sensor cluster with minimum fluctuation esteem and most astounding arrangement execution. Electronic noses have been utilized as a bit of an affirmation of business agrarian related undertakings, which intertwine the developing segments of agronomy, biochemical managing, plant science, cell custom, plant cultivar choices [1].

Contamination is the approach of debasement into the surroundings that causes a couple of exchange the earth round us. Spoiling can take the state of development substances including strong particles, fluid globules, or fuel [2] and quality which wires rattle, warmth, and light. An air poison is a substance recognizable all around that may impact tricky impact people and the natural structure in the around the 
globe. So there's expanding call for territory and following of ozone depleting substances because of ascend in polluted gases [3]. In any case, in this paper we will most likely manage the trademark gases those are passed on by techniques for the solid waste and we can offer regard for Indoor air harms in light of the reality of the situation it's far focal characteristic hazard to success [4]. The best challenges had been learned about zone programs as the most frequently utilized sensors are touchy to shapes in barometrical conditions $[5,6]$. The electronic nostril cause is to consistent after of the surface flood and underwriting of the relationship among the moved nose reactions and notice propel [7]. Quality oversees (QC) of the fragrance attributes of Manufactured stock is of focal criticalness in perspective of reality thing consistency is basic for Maintaining customer seal notoriety and fulfillment [8]. VOCs outpourings are solidly related to the treating the dirt methodology phases [9-11] disclosure of openings of toxic or perilous materials from pipelines or present day plants, and early forewarning of the conglomeration of unsafe fumes. The Figure 1 is showing the functional component of electronic nose that is representing whole the process of odor detection.

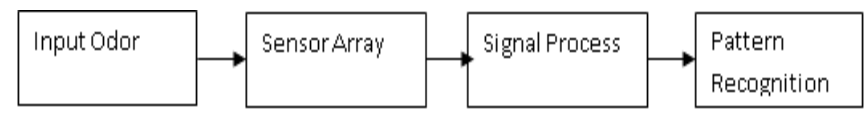

Figure 1. Functional component of Electronic nose

\section{LITERATURE SURVEY}

\subsection{Electronic nose working principle}

The computerized nose transformed into cutting edge so one can emulate human olfaction whose highlights are non-separate component. Basically the instrument incorporates sensor exhibit, test redesign modules, and headspace examining, to produce sign example which can be utilized for portraying smells. One of the primary investigations to evaluate the likelihood of the utilization of an electronic nostril to recognize particular earth pertinent mixes was accomplished in 1995 by method for Hodgins [12].

\subsection{Techniques for pattern recognition}

The investigation included the utilization of two computerized noses, outfitted with MOS sensors, which were moved at conventional time interims to six exceptional positions in the poultry habitation. The sensor response insights had been examined by the PCA to envision the bunching of the estimations Principle Component Analysis (PCA) [13]. Field-recorded insights is urgent for achieving intense field adjustment systems with manufactured toxins total guidelines the utilization of sensor-combination calculations that are pleasantly tuned through regulated training $[14,15]$. The preparation procedure requires a discrete measure of known example information to prepare the framework and is extremely effective in contrasting obscure examples with known references [16]. PCA is touchy to the relative scaling of the first factors. PCA was designed in 1901 by Karl Pearson [17] as a simple of the essential hub hypothesis in mechanics; it was later freely created and named by Harold Hotelling in the 1930s. This prompts flooding of waste and stances cleanliness dangers [18]. Data about sensors of metal oxide is outlined in Table 1.

Table 1. Conduct of normal metal oxides as odor sensors

\begin{tabular}{|c|c|c|}
\hline Material & Disadvantage & Advantage \\
\hline $\mathrm{Ga} 2 \mathrm{O} 3$ & $\begin{array}{l}\text { selectivity is low, sensitivity is } \\
\text { average }\end{array}$ & $\begin{array}{l}\text { stability high, may operate at high temperatures } \\
\text { to oxidizing gases }\end{array}$ \\
\hline $\mathrm{SnO} 2$ & $\begin{array}{l}\text { selectivity is low, depends on } \\
\text { humidity }\end{array}$ & $\begin{array}{l}\text { sensitivity is high, stability is good in } \\
\text { reducing atmosphere conditions }\end{array}$ \\
\hline In2O3 & $\begin{array}{l}\text { stability is low at low oxygen partial } \\
\text { pressure }\end{array}$ & $\begin{array}{l}\text { responds fast as well as fast recovery, } \\
\text { sensitivity is low to humidity }\end{array}$ \\
\hline WO3 & $\begin{array}{l}\text { Sensitivity is low to reducing gases, } \\
\text { dependence on air humidity, slow. }\end{array}$ & $\begin{array}{l}\text { sensitivity is good to oxidizing } \\
\text { gases, thermal stability is good }\end{array}$ \\
\hline CTO & sensitivity is average & stability is high, sensitivity is low to humidity \\
\hline
\end{tabular}

\subsection{Effect of organic gases on environment}

In contrast to fuel, unadulterated ethanol is nontoxic and biodegradable, and it rapidly separates into safe substances whenever spilled [19]. Compound denaturants are added to ethanol to make fuel ethanol, and a considerable lot of the denaturants are poisonous. Like gas, ethanol is an exceedingly combustible fluid and must be transported precisely. CH3)2CO dissipates quickly, even from water and soil. The $\mathrm{CH} 3$ )2CO for fish 
is $8.3 \mathrm{~g} / \mathrm{L}$ of water (or around $1 \%$ ) more than 96 hours, and its natural half-life in water is around 1 to 10 days. $\mathrm{CH} 3) 2 \mathrm{CO}$ may represent a critical danger of oxygen exhaustion in oceanic frameworks because of the microbial utilization. The participatory detecting framework for air contamination checking and control utilizing phones, GPS innovation and sensors to shape a bidirectional versatile detecting data system [20]. In the US, the world's most prosperous country, the child poverty rate is a shocking $22 \%$ [21]. Since propane is regular in the two homes and work environments, the chances of being presented to hazardous centralizations of the gas are well inside reason. Propane is an asphyxiate, which means high centralizations of the gas can cause suffocation. Presentation to high focuses can likewise cause heart failure, obviousness or seizures. Managed contact with the skin can cause frostbite [22]. Propane introduction in lower focuses can likewise cause physical harm, especially to the focal sensory system, lungs and eyes.

\section{METHODOLOGY}

\subsection{Parallel factor analysis (PARAFAC)}

The example part of smell is gotten by making utilization of PARAFAC. PARAFAC (Parallel component examination) is a speculation of PCA (Principle component investigation) to all the more likely request clusters, anyway some of the qualities of the strategy are quite unique in relation to the ordinary comprising of there might be no revolution issue in PARAFAC, and e.g., unadulterated spectra can be recuperated from multi-way otherworldly records. Here, we connected PARAFAC to couple of dimensional clusters. The PARAFAC model can completely utilize the majority of the estimations of the distinction co-exhibit, rather than its fractional estimations as the revealed models [23]. A three-dimensional exhibit might be no ifs ands or buts viewed as a rigid of - dimensional frameworks of the equivalent length. Parallel factor analysis (PARAFAC) is displaying methods for observing unrefined petroleum components [24].

A case for a - dimensional data cluster could be some deliberate variable, say the consideration of ozone (O3) inside the air, at restrictive cases of the day in remarkable geological areas. Two-route varieties of this compose are regularly decayed the utilization of (bilinear) Principal Component Analysis (PCA). The estimations presently wind up contingent upon three factors, and your cluster three-dimensional. PCA can't be executed to 3-dimensional structures as it's miles intrinsically bilinear [25]. Whenever unfurled, the exhibit might be exposed to PCA, however loses its genuine three-dimensional shape. PARAFAC is equipped for work straightforwardly at the three-dimensional cluster and thus grab its genuine piece. An option in contrast to PARAFAC might be given the guide of the Tucker3 calculation, or, in other words more adaptable model of PARAFAC. The Figure 2 is showing the graphical representation of parallel factor analysis and also showing the decomposition of three dimentional data set array. This convert the higher dimentional data to lower dimentional data.

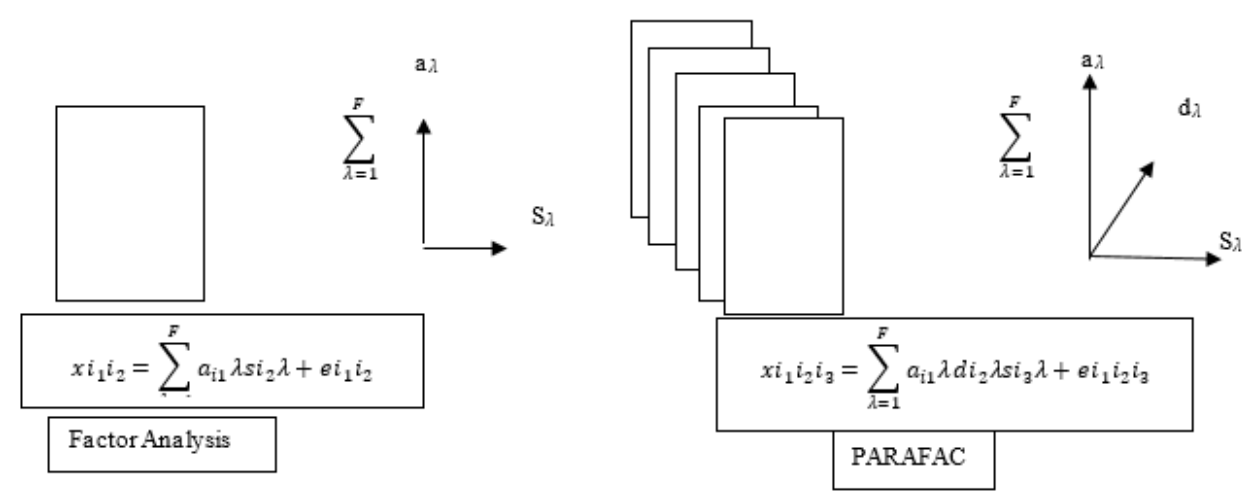

Figure 2. Graphical representation of the factor analysis (left) and PARAFAC based data decomposition of a 3 dimensional data array set (right)

Similar to the other factor analysis methods the PARAFAC is a kind of data decomposition into factor that affects modality. Let $F$ : number of factors with respect to the $\mathrm{j}^{\text {th }}$ slice of the $2^{\text {nd }}$ modality of the array given by:

$$
X^{I \times j \times k}=A^{I \times F} D_{j}^{F \times F} S^{K \times F^{T}}+E^{I \times j \times k}
$$


$D_{j} \mathrm{~s}$ : diagonal matrix with such that the $\mathrm{j}^{\text {th }}$ row of $\mathrm{D}$ is along the diagonal.Similarly for a multi-dimensional data arrays $X^{I_{1} \times I_{2} \times \ldots \ldots . . \times I_{n}}$ higher than $3^{\text {rd }}$ order.

Figure 3 shows the PARAFAC disintegration of the 3 dimensional information cluster in left contrasted with the relating parallel factor examination based decay of 3 dimensional information exhibit by unfurling the third mode into the second mode PCA can't be connected to three-dimensional information such cluster whenever exposed to the PCA loses its actual three-dimensional structure. The blunder minimization performed by exchanging minimum squares (ALS) approach. It iteratively gives the stacking grids A, B, and $\mathrm{C}$ by the calculation given beneath:

1. Pick the quantity of parts, $\mathrm{F}$ (on the decision of $\mathrm{F}$ see next section)

2. Introduce $B$ and $C$

3. Gauge A from $\mathrm{X}, \mathrm{B}$, and $\mathrm{C}$ by slightest square relapse to minimize the square of the mistake

4. Gauge $\mathrm{B}$ and $\mathrm{C}$ in like manner.

5. Rehash from (3) until the converges (indicated by just little changes in fit or loadings)
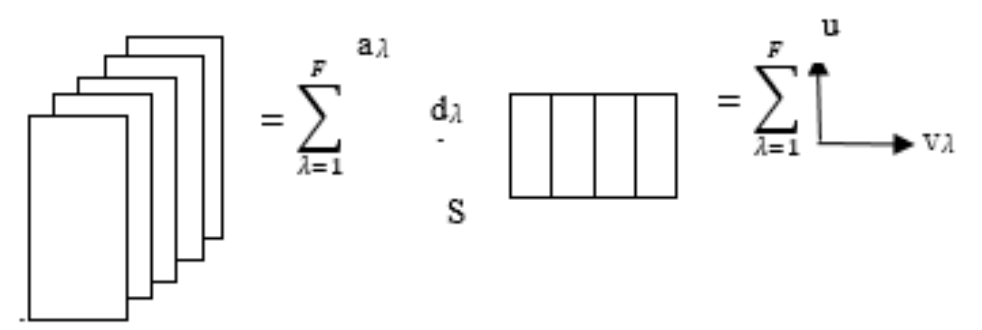

Figure 3. The PARAFAC decomposition of the 3 dimensional data array

\section{RESULTS AND DISCUSSION}

Every sensor reaction is spared as content document at testing recurrence pursues: Segment first: Time, second: Temperature, $3^{\text {rd }}:$ MICS 5521 records, $4^{\text {th }}:$ MICS5135, fifth : TGS2602, sixth : TGS2600, 7th : TGS2611, eighth: TGS 2620. A Matlab code has been created to requests a dataset document, and imports the as indicated by the required length. This informational collection can be discovered online at http://mrpt.org/robotics_datasets.

\subsection{Data information}

For Acetone gas the information estimate is $(9 * 4230 * 6)$ where the quantity of Column=9, information sample $=4230$ and utilized sensors $=6$ as appeared in figure of exploratory informational collection.

For Propane gas information estimate is $(9 * 6191 * 6)$ where the quantity of Column=9, information sample $=6191$ and utilized sensors $=6$ as appeared in figure of trial informational index.

For Ethanol gas the information measure is $(9 * 6807 * 6)$ where the quantity of Column=9, information sample $=6807$ and utilized sensors $=6$ as appeared in figure of exploratory informational collection.

Sensors: MICS 5521= M1, MICS 5135= M2, TGS 2602= T1, TGS 2600= T2, TGS 2611= T3, TGS $2620=\mathrm{T} 4$

From every one of the six sensors we are utilizing blend of three sensors to identify the gases. Acetone $=\mathrm{A}$, Ethanol $=\mathrm{E}$, Propane $=\mathrm{P}$

Good: - Distance between two gases bunches is large means detection is simple.

Average: - Distance between two gases bunches is less yet can be distinguished.

Poor: - Distance between two gases bunches is close/cover.

The outcome assessment is performed to discover the execution of PARAFAC examination on the different sensor clusters. This procedure comprises of correlation of sensor set reaction for three gasses spared in database. The figure demonstrates every one of the means those are required in this exploration work at fires information is recorded and taken from the instrument the apply PARAFAC for just primary sensors after it compute change utilizing score and stacking plot at that point think about outcome as far as bunch covering as good, average, poor. The whole detection process of odor has been shown in Figure 4, this shows that how to get the results from input data set. Firstly we take raw data then we covert higher dimension data to lower dimension data using PARAFAC after that cluster analysis we get the data output in the form of score plot, loading plot, variance plot. 


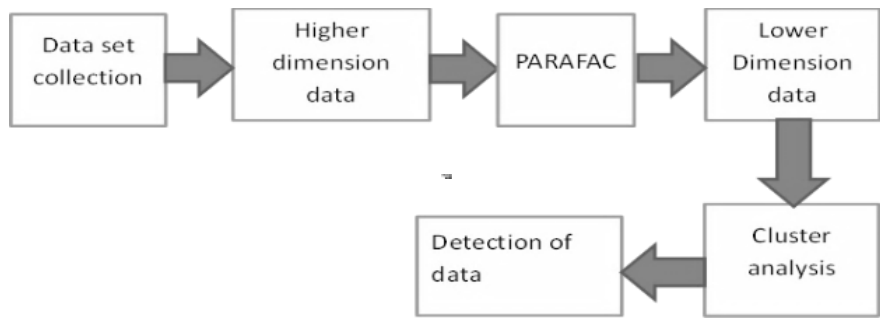

Figure 4. Whole process of detection for the proposed E-Nose system

Scent information gathering has been completed for every one of the examples and trials with following smelling system steps: [0-20]sec: Initially the scent holder was kept shut and isolated from yearning for the first 20 seconds (pattern esteem), [20-30]sec: The jug was opened for these 10 seconds (stablization), [30-90]sec: At 30 seconds, the e-nose goal was brought close to the container, at a separation of $10 \mathrm{~cm}$ and records for 60 seconds, [90-X]sec: Finally source is taken away and e-nose left to come back to pattern state for $10 \mathrm{~min}$ preceding next chronicle. The Table 2 is diplaying the entire six sensor description regarding its detection material, operating voltage range, maximom resistance, and power required.

Table 2. Description of each sensor

\begin{tabular}{llll}
\hline Sensor & Detection Material & Voltage $/ \mathrm{R}_{\text {Base }}$ & Power \\
\hline MICS 5521 & CO, hydrocarbons (HC), and VOC. & $5 \mathrm{~V} \mathrm{DC,74 \Omega}$ & $76 \mathrm{~mW}$ \\
MICS 5135 & CO, HC, ethanol, and VOC. & $3.2 \mathrm{~V}, 97 \Omega$ & $102 \mathrm{~mW}$ \\
TGS 2602 & Ethanol, Ammonia, Hydrogen, Toluene & $5 \mathrm{~V} \mathrm{DC}, 59 \Omega$ & $15 \mathrm{~mW}$ \\
TGS 2600 & Methane, Ethanol, Iso-butane, CO, Hydrogen & $5 \mathrm{~V} \mathrm{DC}, 83 \Omega$ & $15 \mathrm{~mW}$ \\
TGS 2611 & Methane, Ethanol, Iso-butane, Hydrogen & $5 \mathrm{DC}, 59 \Omega$ & $15 \mathrm{~mW}$ \\
TGS 2620 & Methane, Ethanol, Iso-butane, CO, Hydrogen & $5 \mathrm{DC} / \mathrm{AC}, 83 \Omega$ & $15 \mathrm{~mW}$ \\
\hline
\end{tabular}

Figure 5 shows results for the three sensors MICS 5135, TGS 2600, and TGS 2620 (M2T2T4) utilizing PARAFAC. Figure 5(a) demonstrates record for the three sensors MICS 5135, TGS 2600, and TGS 2620 (M2T2T4). In Figure 5(b) Acetone gas group lies in first and second section of PC2 and second and third portion of PC1. E1,E2,E3 are thickness group just in third fragment of PC1 and PC2 however bunch of $\mathrm{P} 1, \mathrm{P} 2, \mathrm{P} 3$ are covering both third and fourth section of PC1 and first and second portion of PC2. Along these lines each of the three sensors are fit for characterizing Propane and Ethanol gases and can segregate Acetone gas in an extremely well way from Propane and Ethanol. Consequently the three sensors exhibit are "great" in arranging (A to P) and (A to E) yet "Normal" in ( $\mathrm{P}$ to E). In stacking plot (Figure 5(c)) TGS2602, TGS2600, MICS5135 are performing close however different sensors are laying in various zones henceforth they performing diversely for all gases and in Figure 5(d) the clarified variance for PC1 is 90.2 and for PC2 is 97.7. The figure 6 is displaying all the 20 combination of variance plot and the minimum value of variance for (M1M2T2) is for PC1 88.9 maximum value of combination (M2T2T4) for PC2 is 97.7.

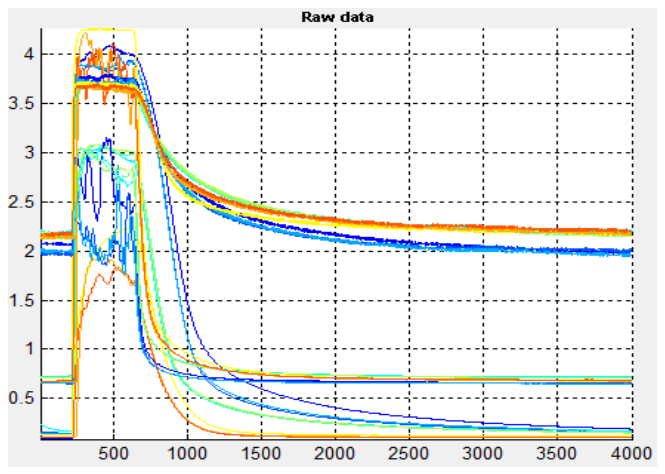

(a)

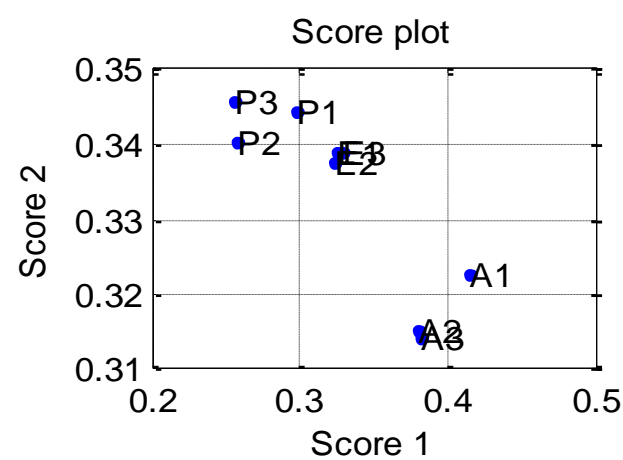

(b)

Figure 5. (a) Raw data plot of sensors, (b) Score plot of sensor array 


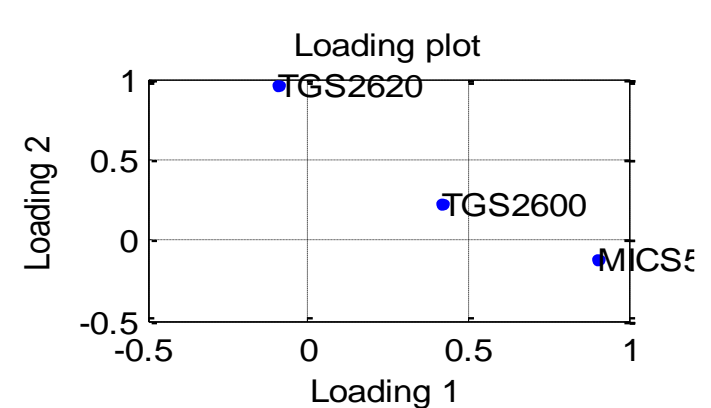

(c)

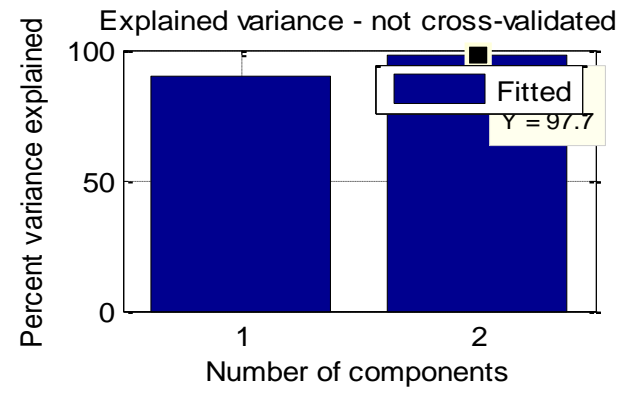

(d)

Figure 5. (c) Loading plot of sensor array, (d) 3 sensor (M2T2T4)

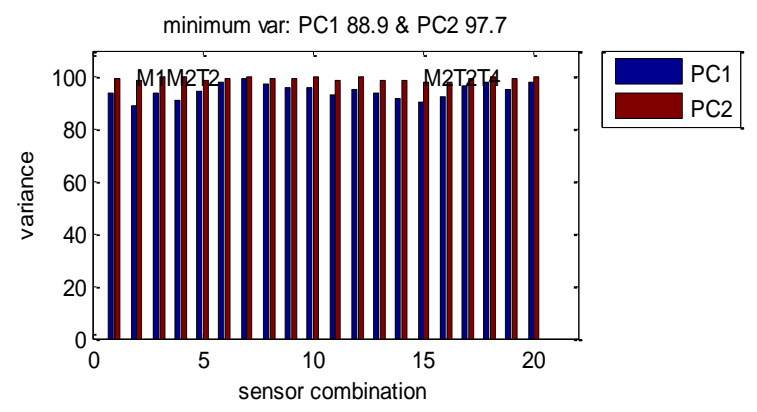

Figure 6. Variance plot for all the combination (20 combinations) of three sensors using PARAFAC

Figure 7 shows results for the three sensors MICS 5135, TGS 2600, and TGS 2620 (M2T2T4) utilizing PCA. Figure 7(a) demonstrates record for the three sensors MICS 5135, TGS 2600, and TGS 2620 (M2T2T4). In Figure 7(b) Acetone gas cluster lies in 1 st and $4^{\text {th }}$ segment of PC2 and $3^{\text {rd }}$ and $4^{\text {th }}$ segment of PC1. E1,E2,E3 are density cluster in third and $4^{\text {th }}$ segment of PC2 and third segment of PC1 but cluster of $\mathrm{P} 1, \mathrm{P} 2, \mathrm{P} 3$ are in $2^{\text {nd }}$ segment of PC2 and 1st segment of PC1. Thus all three sensors are capable of classifying Propane and Ethanol gases and can discriminate Propane gas from Acetone and Ethanol. Thus the three sensors array are "Poor" in classifying (A to P) and (A to E) but "Average" in (P to E).In loading plot (Figure 7(c)) TGS2602, TGS2600, MICS5135 are performing very close but other sensors are lying in different zones hence they performing differently for all gases and in Figure 7(d) the explained variance for PC1 is 99.6 and for PC2 is 99.9 .

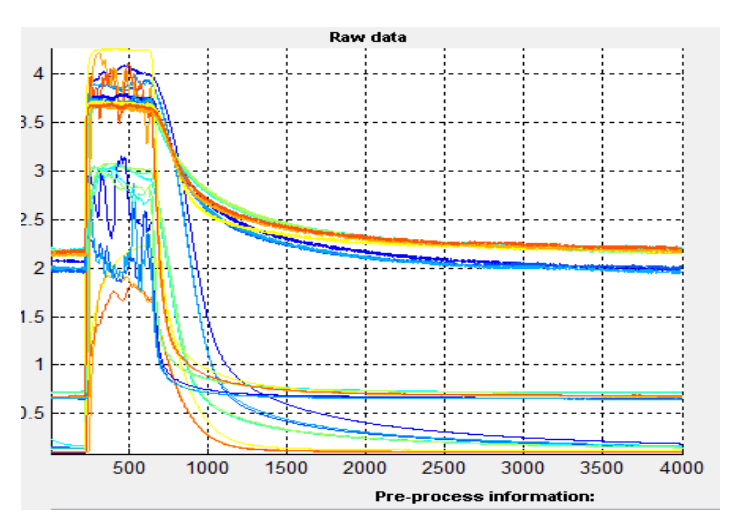

(a)

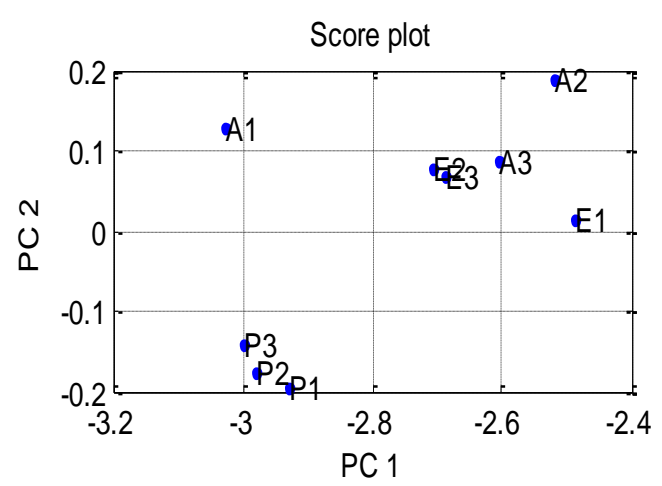

(b)

Figure 7. (a) Raw data record for the sensors, (b) Results using pca (M2tT2T4) score plot, 


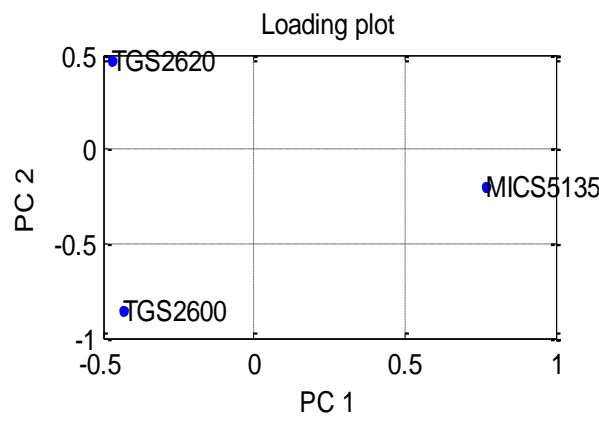

(c)

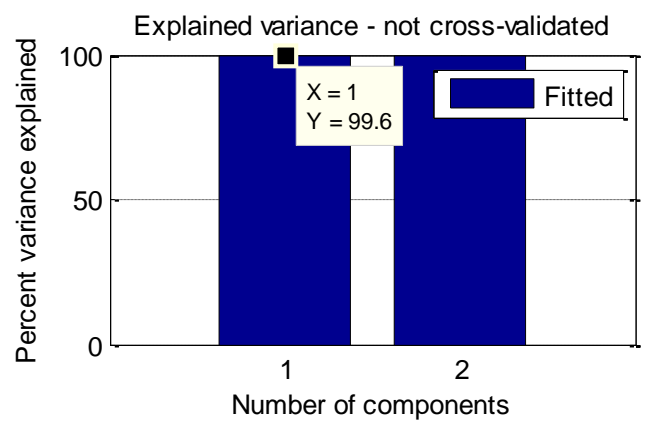

(d)

Figure 7. (c) Results using pca (M2T2T4) loading plot, (d) Results using pca (M2T2T4) variance plot

Sensors: MICS 5521=M1, MICS 5135= M2, TGS 2602=T1, TGS 2600= T2, TGS 2611=T3, TGS $2620=$ T4 . The table 3 is showing all the 20 combination of sensors used in Electronic nose. From all six sensors we are using combination of three sensors to detect the gases. In Table 4 performance of all sensors array of size 3 sensor devices are summarized. Here we have got 20 sensors set combination by using three sensors out of 6 sensors. Sensors results are taken in terms of good, average, poor, non-overlapping of any two gases on the two dimensional principle component axes observe from the score plot PARAFAC analysis. It has been observe that minimum variation index. For array of the sensors the variation index is found to be reduce that is 88.9 to 90.2 along $\mathrm{PC} 1$ and 97.7 to 99.7 along PC2. The best performance in three sensor set is observed for array (M2T2T4). It is showing good classification in AP and EA and average for PE. Hence the optimum sensor set is found to be array of three sensors that is M2T2T4. Thus it validate that it is not necessary that we will get higher accuracy by large number of sensor array. Performance can be improved even small number of sensors but of specific combination.

In Table 4 performance of all sensors array of size 3 sensor devices is shown. There are 20 sensors set combination by using three sensors out of 6 sensors but as above shown M2T2T4 is best using PARAFAC but here we are using PCA so the results are not good. Sensors results are taken in terms of good, average, poor, non-overlapping of any two gases on the two dimensional principle component axes observe from the score plot PCA analysis (Figure 7(b) score plot). It has been observe that minimum variation index is 99.6 and maximum is 99.9 .

Table 3. Results for the combination of THREE sensors Using PARAFAC

\begin{tabular}{ccccccc}
\hline Sr.No. & Sensors & $\begin{array}{c}\text { Acetone } \& \\
\text { Propane }\end{array}$ & $\begin{array}{c}\text { Propane } \& \\
\text { Ethanol }\end{array}$ & $\begin{array}{c}\text { Ethanol \& } \\
\text { Acetone }\end{array}$ & Value On Pc1 & Value On Pc2 \\
\hline 1 & M1M2T1 & Good & Average & Average & 93.5 & Y=99 \\
2 & M1M2T2 & Good & Average & Poor & 88.9 & 98.8 \\
3 & M1M2T3 & Good & Average & Good & 93.4 & 99.7 \\
4 & M1M2T4 & Good & Average & Good & 91.3 & 99.8 \\
5 & M1T2T3 & Good & Poor & Average & 94.1 & 98.5 \\
6 & M1T1T2 & Good & Average & Poor & 97.6 & 99.1 \\
7 & M1T3T4 & Good & Poor & Average & 99.6 & 99.9 \\
8 & M1T1T3 & Good & Average & Poor & 97.5 & 99.6 \\
9 & M1T1T4 & Average & Good & Average & 96 & 99.6 \\
10 & M1T1T4 & Good & Average & Average & 96.1 & 99.8 \\
11 & M2T1T2 & Good & Good & Average & 93.2 & 98.3 \\
12 & M2T3T4 & Good & Average & Good & 95.4 & 99.8 \\
13 & M2T1T3 & Good & Average & Good & 93.8 & 98.9 \\
14 & M2T1T4 & Good & Average & Average & 91.7 & 98.7 \\
15 & M2T2T4 & Good & Average & Good & 90.2 & 97.7 \\
16 & M2T2T3 & Good & Average & Good & 92.5 & 98 \\
17 & T1T2T3 & Good & Average & Good & 96.5 & 99.1 \\
18 & T2T3T4 & Good & Average & Average & 97.9 & 99.7 \\
19 & T1T2T3 & Good & Average & Poor & 94.9 & 99 \\
20 & T1T3T4 & Good & Average & Average & 97.6 & 99.7 \\
\hline
\end{tabular}

Table 4. Results of combination of THREE sensors Using PCA

\begin{tabular}{ccccccc}
\hline Sr.No. & Sensors & $\begin{array}{c}\text { Acetone \& } \\
\text { Propane }\end{array}$ & $\begin{array}{c}\text { Propane \& } \\
\text { Ethanol }\end{array}$ & $\begin{array}{c}\text { Ethanol \& } \\
\text { Acetone }\end{array}$ & Value On Pc1 & Value On Pc2 \\
\hline 1 & M2T2T4 & Poor & Average & Poor & 99.6 & 99.9 \\
\hline
\end{tabular}




\section{CONCLUSION}

The genuine accomplishment of the sensor organize innovation depends for the most part on its application in destroying a destructive circumstance or in keeping up a decent one. Air quality checking is an imminent application area which is of specific incentive to our nation. Expansive urban communities with high grouping of industry, escalated transport systems and high populace thickness are real wellsprings of air contamination. Here we have finished up the all information identified with sensors and the charts those are profitable for this work. Presently we can state that by utilizing three sensors we can give the less difference and minimal effort instead of utilizing six sensors. All the sensor mix given above however just MICS 5135, TGS 2600 TGS2620 mix (M2T2T4) give the best outcome in regard of gas discovery of gases as CH3)2CO gas in an extremely well way from Propane and Ethanol. Subsequently the three sensors exhibit are "good" in ordering (A to P) and (A to E) however "Average" in (P to E).In stacking plot TGS2602, TGS2600 are performing close yet different sensors are lying in various zones henceforth they performing diversely for all gases and in Fig 5 (d) the clarified variance change for PC1 is 90.2 and for PC2 is 97.7. So it is giving best outcomes utilizing PARAFAC. However, utilizing PCA M2T2T4 isn't giving great outcomes. So we can presume that rather than 6 sensors just 3 sensors set mix give best outcomes utilizing PARAFAC however not with PCA. As compare with PARAFAC for PCA have poor results on using same number of sensors. So PARAFAC is better than PCA.

\section{ACKNOWLEDGEMENT}

All authors would like to thanks Integral University, Lucknow that has provided me MCN number IU/R\&D/2018.MCN000425 for the present research work.

\section{REFERENCES}

[1] A. D. Wilson, "Diverse Applications of Electronic-Nose Technologies in Agriculture and Forestry," Sensors, vol. 13, pp. 2295-2348, 2013

[2] D. A. Burns, et al., "Acid rain and its environmental effects: Recent scientific advances," Atmospheric Environment, vol. 146, pp. 1-4, 2016.

[3] C. Chemel, et al., "Odour-Impact Assessment around a Landfill Site from Weather-Type Classification, Complaint Inventory and Numerical Simulation," Journal of Environmental Management, vol. 93, pp. 85-94, 2012.

[4] S. Tozlu, et al., "Wi-Fi enabled sensors for internet of things: a practical approach," IEEE Communications Magazine, vol/issue: 50(6), pp. 134-143, 2012.

[5] T. Nakamoto and E. Sumitimo, "Study of robust odor sensing system with auto-sensitivity control," Sens. Actuators B Chem., vol. 89, pp. 285-291, 2003.

[6] M. Dipanjali, et al., "Emission, Speciation, and Evaluation of Impacts of Non-Methane Volatile Organic Compounds from Open Dump Site," Journal of the Air \& Waste Management Association, vol. 64, pp. 834-845, 2014.

[7] C. A. McLinden, et al., "Space-based detection of missing sulfur dioxide sources of global air pollution," Nature Geoscience, vol/issue: 9(7), pp. 496-500, 2016.

[8] A. D. Wilson, et al., "M. Applications and advances in electronic-nose technologies," vol. 9, pp. 5099-5148, 2009.

[9] D. Rodríguez, et al., "Effect of control parameters on emitted volatile compounds in municipal solid waste and pine trimmings composting," J. Environ. Sci. Health A Toxic/Hazard. Subst. Environ. Eng., vol. 45, pp. 855-862, 2010.

[10] B. F. Staley, et al., "Release trace organic compounds during the decomposition of municipal solid waste components," Environ. Sci. Technol., vol. 40, pp. 5984-5991, 2006.

[11] A. Sanchez, "A kinetic analysis of solid waste composting at optimal conditions," vol. 27, pp. 854-855, 2007.

[12] Nayak R., et al., "IoT Based Air Pollution Monitoring System," Imperial Journal of terdisciplinary Research (IJIR), pp. 571-575, 2017.

[13] G. Keshri, et al., "Differentiation of Agaricus species and other homobasidiomycetes based on volatile production patterns using an electronic nose system," Mycol. Res., vol/issue: 107(5), pp. 609-613, 2003.

[14] L. Liu, et al., "Vector-sensor-based signal parameter estimation by exploiting cpd of tensors," IEEE Sens. Lett., vol. 2, pp. 1-4, 2018

[15] R. J. Payne, et al., "Nitrogen deposition and plant biodiversity: past, present, and future," Frontiers in Ecology and the Environment, vol/issue: 15(8), pp. 431-436, 2017.

[16] A. Zhao, et al., "An improved aerial target localization method with a single vector sensor," Sensors, vol. 17, pp. 2619, 2017.

[17] K. Balakrishnan, et al., "Household Air Pollution Exposures of Pregnant Women Receiving Advanced Combustion Cookstoves in India: Implications for Intervention,” Annals of Global Health, vol. 81, pp. 375-385, 2015.

[18] Marshall R. E. and Farahbakhsh K., "Systems approaches to integrated solid waste management in developing countries," Waste Management, vol/issue: 33(4), pp. 988-1003, 2013.

[19] I. T. Ekeu-wei, et al., "Assessment of environmental impact of solid waste dumpsites using remote sensing," Nigerian journal of technology (nijotech), vol/issue: 37(1), pp. 275-285, 2018. 
[20] Mendez D., "P-Sense: A Participatory Sensing System for Air Pollution Monitoring and Control," IEEE International Conference on PERCOM Workshops, vol/issue: 6(3), pp. 344-347, Mar 2017.

[21] Perera F. P., et al., "Combined effects of prenatal exposure to polycyclic aromatic hydrocarbons and material hardship on child adhd behavior problems," Environ. Res., vol. 160, pp. 506-513, 2018.

[22] M. F. WallisDeVries and R. Bobbink, "Nitrogen deposition impacts on biodiversity in terrestrial ecosystems: Mechanisms and perspectives for restoration," Biological Conservation, vol. 212, pp. 387-389, 2017.

[23] W. G. Mendoza, et al., "Application of fluorescence and PARAFAC to assess vertical distribution of subsurface hydrocarbons and dispersant during the Deepwater Horizon oil spill," Environ. Sci.: Processes Impacts, vol. 15, pp. 10172013.

[24] W. Rao, et al., "A Novel PARAFAC Model for Processing the Nested Vector-Sensor Array," Sensors, vol. 18, pp. 3708, 2018.

[25] L. Cheng, et al., "Probabilistic tensor canonical polyadic decomposition with orthogonal factors," IEEE Trans. Signal Process, vol/issue: 65(3), pp. 663-676, Feb 2017.

\section{BIOGRAPHIES OF AUTHORS}

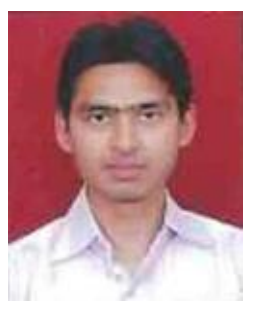

Shri Om Mishra received his bachelor degree in 2009 from bbdnitm lucknow india and received his M.tech degree with honors in 2014 from integral university lucknow, india and got silver medal by Governor of utter Pradesh. He has two research papers in reputed journals.

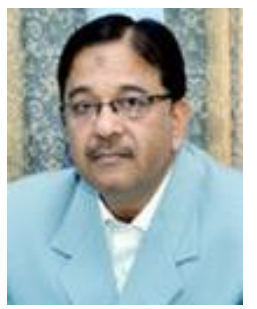

Syed Hasan Saeed did B.Tech in Electrical Engineering from Zakir Hussain College of Engineering and Technology, campus college of Aligarh Muslim University (AMU), Aligarh, Uttar Pradesh in year 1992 and received $\mathrm{PhD}$ from Integral University, Lucknow in year 2010. Currently working as Professor and Head of the Department in Electronics \& Communication Engineering department, Faculty of Engineering at Integral University. He has many sesearch papers in reputed journals. 